\title{
Double pylorus secondary to recurrent ulcer: serial endoscopy follow-up
}

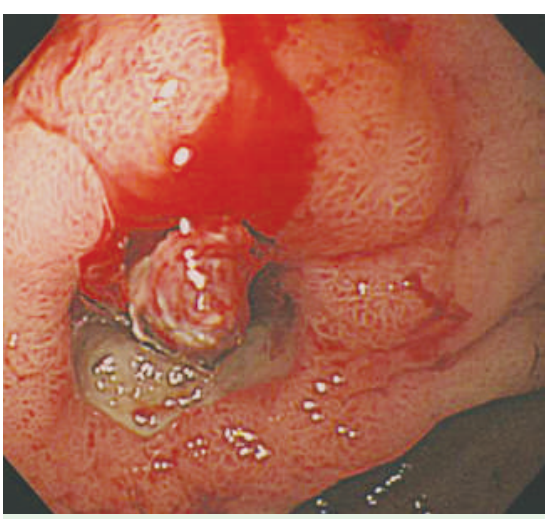

Fig. 1 The first endoscopic finding, showing an active ulcer bleeding in the lesser curve of the gastric antrum.

A 67-year-old man with alcoholic liver disease underwent esophagogastroduodenoscopy (EGD) as follow-up to gastric ulcer. Eleven months earlier he had been hospitalized because of hematemesis and melena. The EGD noted a bleeding gastric ulcer at the lesser curve of the gastric antrum ( Fig. 1). Subsequently, following endoscopic hemoclipping, he was treated with a proton pump inhibitor (PPI) for 1 month. Thereafter he remained well. However, he was lost to follow-up, and treated intermittent epigastric pain with self-prescribed antacids. Eight months later, he revisited our hospital due to persistent epigastric pain. EGD showed an ulcerative lesion in the same area as before ( $\bullet$ Fig. 2). Over the next 3 months he experienced intermittent episodes of epigastric soreness; however, generally he was much improved over his previous condition and intermittently took antacids. EGD performed 11 months after the first endoscopy, revealed an accessory pyloric canal on the lesser curve of the antrum, where the ulcer had been observed previously. The gastric antrum and bulb had become connected by two openings separated by a septum, which is an acquired complication of recurrent gastric ulcer ( Fig.3a). The scope could enter the duodenal bulb through either the pyloric or the accessory canal ( $\bullet$ Fig. $\mathbf{3 b}$ ).

The prevalence of double pylorus is reportedly about $0.02 \%$ to $0.4 \%[1,2]$. Most of the fistulas were located on the lesser curve aspect of the gastric antrum and duodenal bulb. For ulcers in these locations, the route of penetration enters the

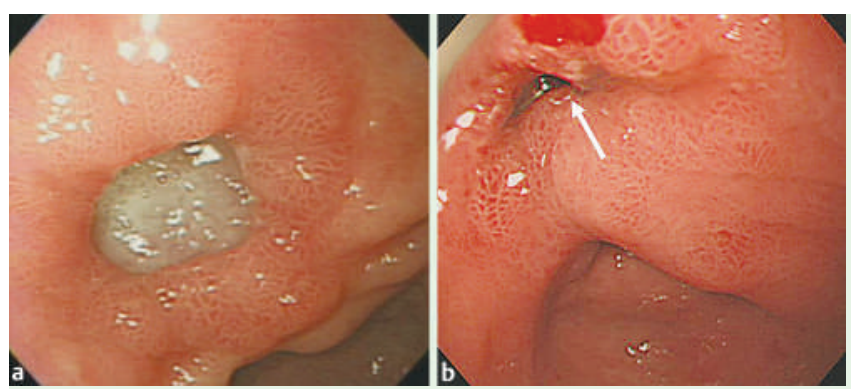

Fig. 2 (a) After 1 month, decreased ulcer base with re-epithelization and a fistula-like opening (arrow), in which the scope cannot pass the opening lesion, were noted on the previous ulcer lesion.

(b) Eight months later, the esophagogastroduodenoscopy shows an ulcerative lesion in the same area.

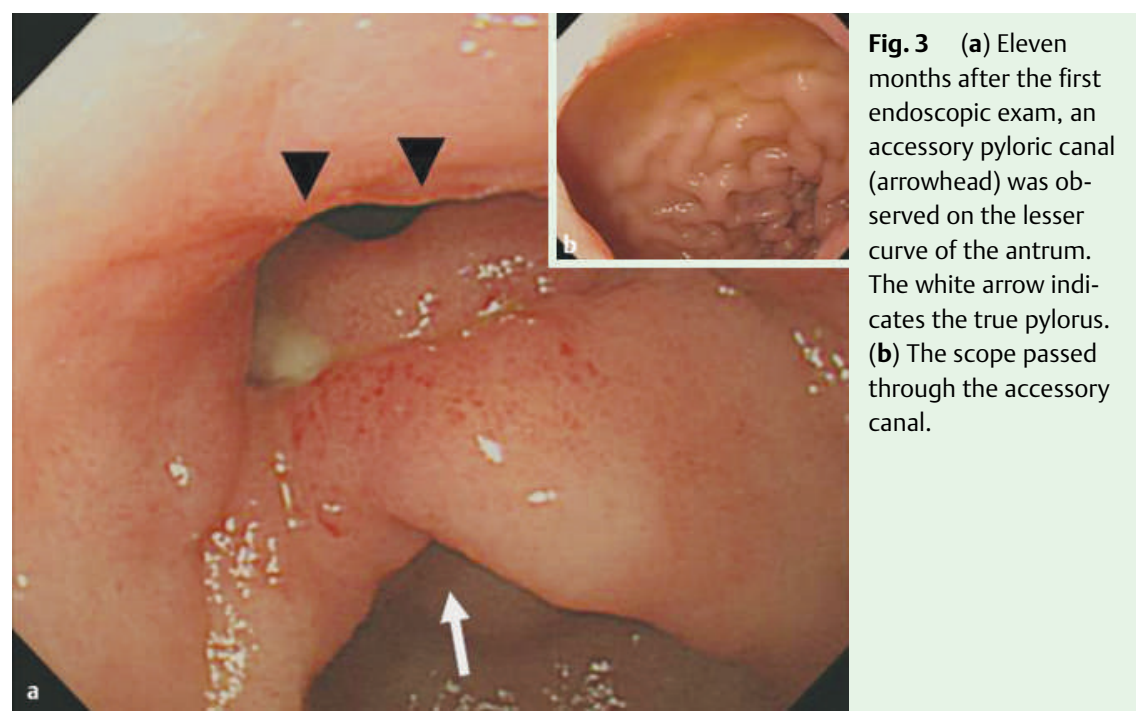

superior aspect of the duodenal bulb. In most cases, double pylorus is an acquired complication of ulcer diseases [2,3]. However, some cases have been reported in which double pylorus was evidently a congenital anomaly [1]. This rare case shows serial endoscopic findings of recurrent gastric ulcers that led to the formation of a double pylorus.

Endoscopy_UCTN_Code_CCL_1AB_2AD_3AC

\section{T. H. Lee, S. H. Park}

Division of Gastroenterology,

Department of Internal Medicine,

University of Soonchunhyang College of

Medicine, Cheonan Hospital, Cheonan,

South Korea

\section{References}

1 Hegedus V, Poulsen PE, Reichardt J. The natural history of the double pylorus. Radiology $1978 ; 126: 29-34$
2 Hu TH, Tsai TL, Hsu CC et al. Clinical characteristics of double pylorus. Gastrointest Endosc 2001; 54: $464-470$

3 Akazawa Y, Mizuta Y, Osabe M et al. A case of double pylorus caused by recurrent gastric ulcers: a long-term endoscopic observation. Dig Dis Sci 2005; 50: 2125-2128

\section{Bibliography}

DOI $10.1055 / \mathrm{s}-2008-1077456$

Endoscopy 2008; 40: E226

(c) Georg Thieme Verlag KG Stuttgart · New York . ISSN 0013-726X

\section{Corresponding author}

\section{T. H. Lee, MD}

Division of Gastroenterology

Department of Internal Medicine

Soonchunhyang University Cheonan Hospital

23-20 Bongmyeong-dong

Cheonan-si

Chungcheongnam-do

South Korea

330-721

Fax: $+82-41-5745762$

thlee9@lycos.co.kr or leetaehoon9@hanmail.net 